\title{
A Critical Role of the Strychnine-Sensitive Glycinergic System in Spontaneous Retinal Waves of the Developing Rabbit
}

\author{
Z. Jimmy Zhou \\ Departments of Physiology and Biophysics and Ophthalmology, University of Arkansas for Medical Sciences, Little Rock,
} Arkansas 72205

In the developing vertebrate retina, spontaneous electric activity occurs rhythmically in the form of propagating waves and is believed to play a critical role in activity-dependent visual system development, including the establishment of precise retinal and geniculate circuitry. To elucidate how spontaneous retinal waves encode specific developmental cues at various developmental stages, it is necessary to understand how the waves are generated and regulated. Using $\mathrm{Ca}^{2+}$ imaging and patch clamp in a flat-mount perinatal rabbit retinal preparation, this study demonstrates that, in addition to the cholinergic system, a strychnine-sensitive system in the inner retina plays an obligatory and developmentally regulated role in the initiation and propagation of spontaneous retinal waves. This system, which is believed to be the glycinergic network, provided an excitatory drive during early retinal development. It then became inhibitory after postnatal day 1 (P1) to P2, an age when a number of coordinated transitions in neurotransmitter systems occurred concomitantly, and finally contributed to the complete inhibition and disappearance of spontaneous waves after P7-P9. This glycinergic contribution was notably distinct from that of the ionotropic GABAergic system, which was found to exert an inhibitory but nonessential influence on the early wave formation. Blocking glycine- and GABA-gated anion currents had opposing effects on spontaneous retinal waves between embryonic day 29 and $\mathrm{PO}$, suggesting that $\mathrm{Cl}^{-}$transporters, particularly $R(+)$-butylindazone-sensitive $\mathrm{K}-\mathrm{Cl}$ cotransporters, may have a synapse- and/or cell type-specific distribution pattern, in addition to an age-dependent expression pattern in the inner retina. Overall, the results revealed an important reliance of spontaneous retinal waves on dynamic and coordinated interactions among multiple, nonredundant neurotransmitter systems.

Key words: visual development; spontaneous retinal waves; cholinergic; glycinergic and GABAergic amacrine cells; $\mathrm{K}-\mathrm{Cl}$ cotransporters; rabbit retina
During the development of the vertebrate retina, ganglion cells and some interneurons undergo spontaneous rhythmic bursts of excitation long before the onset of vision (Masland, 1977; Maffei and Galli-Resta, 1990; Meister et al., 1991; Sernagor and Grzywacz, 1995; Catsicas et al., 1998; Wong et al., 1998; Zhou, 1998; Feller, 1999; O’Donovan, 1999; Wong, 1999). This activity propagates laterally as waves in local regions of the inner retina and is believed to play important functional roles in activity-dependent neurodevelopment, such as the refinement of precise neuronal connectivity in the visual system (Constantine-Paton et al., 1990; Cline, 1991; Goodman and Shatz, 1993; Katz and Shatz, 1996; Sernagor and Grzywacz, 1996; Penn et al., 1998). Although the exact cellular mechanism underlying the spontaneous retinal wave is unclear, it is thought that neurotransmitter-mediated interactions are instrumental in the generation and propagation of the wave (Feller et al., 1996; Catsicas et al., 1998; Fischer et al., 1998; Wong et al., 1998; Zhou, 1998; Sernagor and Grzywacz, 1999; Stellwagen et al., 1999; Sernagor et al., 2000; Zhou and Zhao, 2000).

In the mammalian retina, for example, the nicotinic cholinergic

\footnotetext{
Received Jan. 9, 2001; revised April 24, 2001; accepted April 27, 2001.

This study was supported by National Institutes of Health Grant RO1 EY01894 and Research to Prevent Blindness, Inc. I thank Drs. Sunil Paul, Dichen Zhao, and Michael Jennings for scientific discussions and Krisanne Morgan for technical assistance.

Correspondence should be addressed to Dr. Z. Jimmy Zhou, Department of Physiology and Biophysics, University of Arkansas for Medical Sciences, Mail Slot 505, Little Rock, AR 72205-7199. E-mail: zhoujimmy@uams.edu.

Copyright (C) 2001 Society for Neuroscience 0270-6474/01/215158-11\$15.00/0
}

system has been shown to provide the major fast excitatory drive for spontaneous waves during the early stage of wave development (the early wave) (Feller et al., 1996), presumably through starburst amacrine cells (Zhou, 1998). As development proceeds, the nicotinic drive for the wave diminishes and is replaced by the glutamatergic (Bansal et al., 2000; Wong et al., 2000; Zhou and Zhao, 2000) and muscarinic (Zhou and Zhao, 2000) drives through two coordinated transitions in the neurotransmitter systems. These and other recent results (Fischer et al., 1998; Stellwagen et al., 1999) indicate that interactions among the underlying neurotransmitters are dynamic and complex and that multiple neurotransmitter systems may be involved in the formation and modulation of spontaneous retinal waves.

To identify additional neurotransmitter systems that play essential and concerted roles in forming retinal waves at various stages of development, this study investigated the contribution of glycine and GABA systems to spontaneous retinal waves in perinatal rabbits. The results show that strychnine-sensitive neurotransmission is obligatory in the production of early [before postnatal day 1 (P1), or $<77 \%$ caecal period] (cf. Dreher and Robinson, 1988) retinal waves and that both fast cholinergic and glycinergic systems, but not the fast GABAergic or fast glutamatergic system, are essential for the early wave formation in rabbits. The glycinergic input was excitatory during the early wave. It then underwent a drastic transition to an inhibitory drive immediately after P0-P1, with a time course similar to that of the emergence of the glutamatergic and muscarinic drives for the late wave (Zhou and Zhao, 2000). In contrast, the fast GABAergic system 
had an overall inhibitory influence on both early and late retinal waves in rabbits [embryonic day 26 (E26) to P9], indicating that $\mathrm{GABA}_{\mathrm{A} / \mathrm{C}}$ receptor-mediated inhibition in the inner retina developed earlier than did the glycinergic inhibition. The opposing effects of GABA and glycine on the early retinal wave suggest that, during certain developmental stages (E29-P1), different levels of intracellular chloride concentrations might be associated with GABAergic and glycinergic postsynaptic sites.

\section{MATERIALS AND METHODS}

Calcium imaging and patch clamp in the flat-mount rabbit retina. Retinal flat mounts were prepared from pigmented (New Zealand Red) and albino (New Zealand White) rabbits aged between E26 (gestation period of $31 \mathrm{~d}$ ) and P13 as described previously (Zhou, 1998; Zhou and Zhao, 2000). No significant differences were noticed between the two strands of rabbits with respect to the results reported here. Embryonic rabbits were delivered by caesarian section. All procedures involving the use of animals were according to the National Institutes of Health guidelines as implemented by the institutional animal care and use committee.

Procedures for calcium imaging in the flat-mount rabbit retina were as described previously (Zhou and Zhao, 2000). In brief, the retina was isolated from the pigment epithelium at $4^{\circ} \mathrm{C}$ in HEPES-based Ames medium, which was modified from Ames medium (Ames and Nesbett, 1981) by replacing $\mathrm{NaHCO}_{3}$ with $20 \mathrm{~mm}$ HEPES. Vitreous, immature Müller cell end feet, and ganglion cell axon fibers that cover the ganglion cell layer were partially removed mechanically. Pieces of the isolated retina were loaded with the fluorescent dye fura-2 AM $(10 \mu \mathrm{M}$ with $0.001 \%$ pluronic acid) in HEPES-based Ames medium at $25-30^{\circ} \mathrm{C}$. During $\mathrm{Ca}^{2+}$ imaging and patch-clamp recording, the recording chamber was continuously superfused $(3-4 \mathrm{ml} / \mathrm{min})$ with Ames medium preheated to $35-37^{\circ} \mathrm{C}$. Cells in the ganglion cell layer were imaged with an intensified, cooled CCD camera (Intensified Pantamax; Roper Scientific Instruments, Princeton, NJ) mounted on a fixed-stage, upright microscope (Olympus BX50WI; Olympus USA, New York, NY). The excitation wavelength was $380 \mathrm{~nm}$, and the emission fluorescence was measured at $500 \mathrm{~nm}$ wavelength. All pharmacological agents used in this study were purchased from Sigma (St. Louis, MO) and were applied to the retina by either bath perfusion (dead volume, $\sim 2 \mathrm{ml}$ ) or pressure injection (Lukasiewicz and Werblin, 1990) with a Picospritzer-II (General Valve, Fairfield, NJ) and puffer pipettes pulled from multibarrel or $\theta$-shaped glass tubing (World Precision Instruments, Sarasota, FL). Ames and HEPES-based Ames media were always saturated with carbogen $\left(95 \% \mathrm{O}_{2}, 5 \% \mathrm{CO}_{2}\right)$ and oxygen, respectively.

Whole-cell patch-clamp recordings were made from cells in the ganglion cell layer of the flat-mount rabbit retina as described previously (Zhou, 1998). Simultaneous patch-clamp and $\mathrm{Ca}^{2+}$ imaging were made from fura-2 AM-loaded retina under a $40 \times$ water immersion objective lens (Zhou and Zhao, 2000). The presence of a dye-free patch pipette in the field of view did not interfere with fluorescence imaging of retinal waves. The pipette resistance was 3-5 M $\Omega$ measured in Ames medium and a standard pipette solution containing (in $\mathrm{mM}$ ): $95 \mathrm{~K}$-gluconate, 15 $\mathrm{KCl}, 5 \mathrm{NaOH}, 0.5 \mathrm{CaCl}_{2}, 2 \mathrm{MgCl}_{2}, 5 \mathrm{EGTA}, 2 \mathrm{ATP}, 0.5 \mathrm{GTP}, 2$ ascorbic acid, and 10 HEPES, pH 7.2. Series resistance was compensated by $50-80 \%$ with the series resistance compensation circuitry in the patchclamp amplifier (Axopatch 200B; Axon instruments, Foster City, CA).

Data acquisition and analysis. Fluorescence images were collected with Axon Imaging Workbench (AIW) software (Axon Instruments) and analyzed with AIW and Scion Image (Scion Corp., Frederick, MD). To monitor bursts of spontaneous activity in the retina, oval zones were drawn around individual dye-loaded cells or groups of cells with AIW software. The average fluorescence intensity in each zone was plotted as a function of time $F(t)$ with AIW. The relative change in the emission fluorescence intensity $(\Delta F / F)$ was defined as $\left[F(t)-F_{\mathrm{o}}(t)\right] / F_{\mathrm{o}}(t)$, where $F_{\mathrm{o}}(t)$ was the baseline intensity. The slowly changing baseline fluorescence intensity, $F_{\mathrm{o}}(t)$, was approximated by fitting $F(t)$ with adjacent averaging using the Origin software (Origin Lab, Northampton, MA). The result of the fit, $F_{\text {fit }}(t)$, closely resembled the slowly varying baseline fluorescence intensity $\left(F_{\mathrm{o}}\right)$ without the rhythmic bursting activity. Thus, $\Delta F / F$ was approximated as $\left[F(t)-F_{\text {fit }}(t)\right] / F_{\text {fit }}(t)$ using the Origin software (Zhou and Zhao, 2000). For simplicity, only a small number (two to six) of randomly selected zones were shown in most figures, but similar results were also found from most of the remaining cells in the field of view.
The propagation of waves was imaged under a $10 \times$ objective lens. Differential images $(\Delta F)$ of the wave were obtained by subtracting a control image (averaged from four to eight frames recorded immediately before a wave) from images recorded during the wave with Scion Image software. The contrast of the differential images was enhanced by a fixed percentage with Adobe Photoshop (Adobe Systems, San Jose, CA).

Patch-clamp data were acquired with pClamp8 software (Axon Instruments) and analyzed with Origin (Origin Lab). Synchronous acquisition of patch-clamp and imaging data were made with pClamp8 and AIW software running synchronously.

\section{RESULTS \\ Strychnine-sensitive neurotransmission is critical for early retinal waves in rabbits}

Spontaneous retinal waves were recorded with $\mathrm{Ca}^{2+}$ imaging from the ganglion cell layer of retinal pieces isolated from E26-P9 (63-97\% caecal period) rabbits. Changes in the intracellular free $\mathrm{Ca}^{2+}$ concentration $\left([\mathrm{Ca}]_{\mathrm{i}}\right)$ in ganglion and displaced amacrine cells were measured as relative changes in the emission fluorescence intensity $(\Delta F / F)$ from fura-2-loaded cells. Rhythmic bursts of excitation corresponding to increases in $[\mathrm{Ca}]_{\mathrm{i}}$ (downward deflections in $\Delta F / F$ ) (Fig. $1 A-C$ ) were detected in local areas of the retina. The bursting activity propagated laterally at $100-300 \mu \mathrm{m} / \mathrm{sec}$ in the form of waves. Figure $1, D$ and $E$, shows two typical waves, one propagated in a circular direction, and the other had an irregular shape. Detailed spatiotemporal dynamics of the waves in the developing rabbit retina will be described elsewhere.

Spontaneous waves in the rabbit retina occurred during an extended period of development. At the earliest age tested (E26), the waves were already present, and they continued to remain active until the end of the first postnatal week. After P6-P7, spontaneous waves became much less robust and were detected only in a small percentage of retinas tested. The waves eventually disappeared completely shortly before eye opening (P10-P11).

To identify neurotransmitter systems that play an obligatory role in mediating the early retinal wave, various combinations of specific blockers of common neurotransmitter receptors were tested on spontaneous retinal waves between E29 and P0. Figure 1 shows spontaneous retinal waves recorded from an E29 rabbit retina before and after the application of a cocktail of CNQX (5 $\mu \mathrm{M})$, AP-7 $(100 \mu \mathrm{M})$, picrotoxin $(50 \mu \mathrm{M})$, and atropine $(1 \mu \mathrm{M})$ to block NMDA and non-NMDA glutamate receptors, GABA $\mathrm{A}_{\mathrm{A}}$ and $\mathrm{GABA}_{\mathrm{C}}$ receptors, and muscarinic receptors. The spontaneous wave persisted in the presence of this cocktail, suggesting that none of the respective transmitter systems, either singly or in combination, was essential for the generation and propagation of early retinal waves in rabbits (Fig. $1 A, C, E$ ).

On the other hand, application of strychnine $(0.5-4 \mu \mathrm{M})$ consistently blocked the wave in a reversible manner (Fig. 1F), indicating that strychnine-sensitive neurotransmissions played a critical role in the formation of early spontaneous retinal waves. Likewise, the nicotinic antagonist hexamethonium (Fig. $1 G$ ) or D-tubocurare also blocked the wave, consistent with previous results in the same preparation (Zhou and Zhao, 2000). Hexamethonium $(100 \mu \mathrm{M})$ also completely and reversibly blocked $1 \mathrm{~mm}$ ACh puff-induced transient increases of free $\left[\mathrm{Ca}^{2+}\right]$ in fura-2 AM-loaded cells in the ganglion cell layer of the E29 rabbit retina; however, $4 \mu \mathrm{M}$ strychnine had no detectable inhibitory effect on $\mathrm{Ca}^{2+}$ rises elicited by such ACh puffs in the same cells (data not shown). Patch-clamp recordings from ganglion cells also found no significant inhibition of ACh-evoked currents by $4 \mu \mathrm{M}$ strychnine at this age (date not shown). These results suggest that 

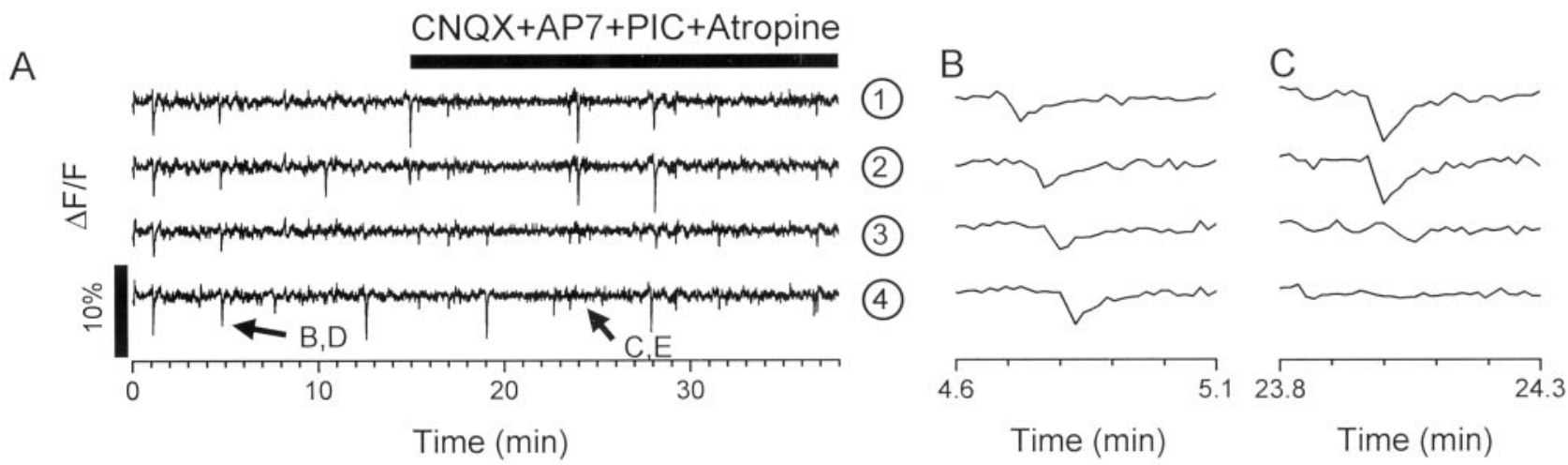

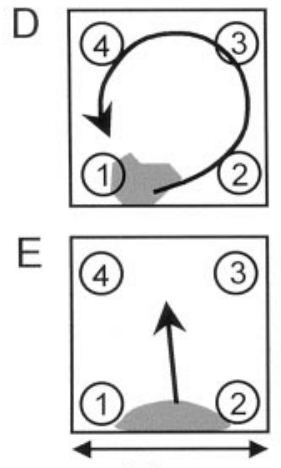

$1.1 \mathrm{~mm}$
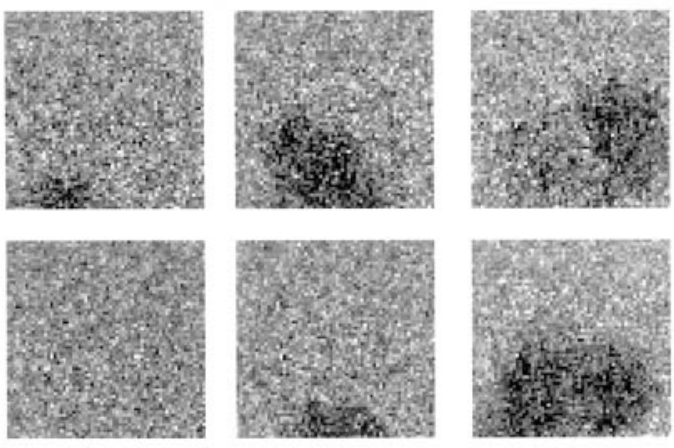

$1.8 \mathrm{~s}$

F

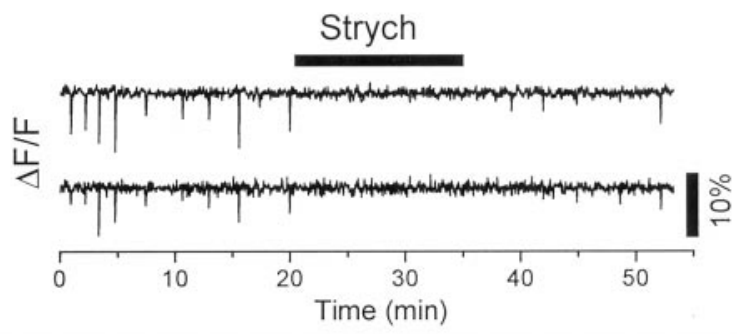

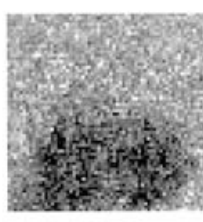

$3.6 \mathrm{~s}$
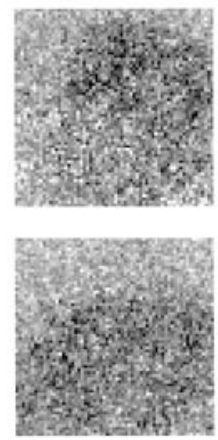

$5.4 \mathrm{~s}$
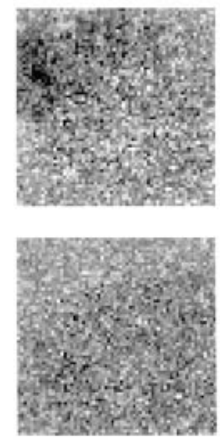

$7.2 \mathrm{~s}$
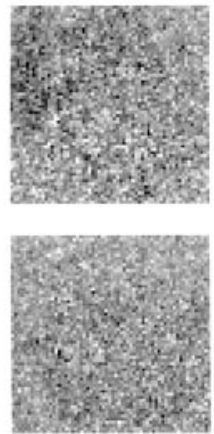

$9.0 \mathrm{~s}$

G

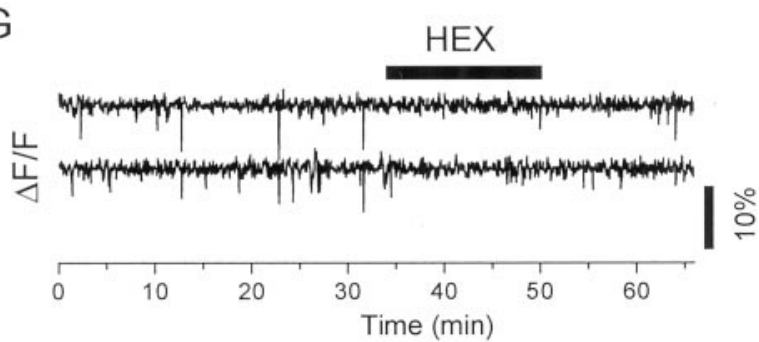

Figure 1. Spontaneous waves of rhythmic activity in an E29 rabbit retina recorded under a $10 \times$ objective lens. $A$, Relative (percentage) changes in fluorescence intensity measured from four round areas marked 1 through 4 in the field of view shown in $D$ and $E$. Downward deflections in the traces indicate increases in intracellular free $\mathrm{Ca}^{2+}$ concentrations, which occurred in rhythmic bursts and persisted after bath application of a combination of CNQX $(5 \mu \mathrm{M})$, D-AP-7 $(100 \mu \mathrm{M})$, picrotoxin $(P I C ; 50 \mu \mathrm{M})$, and atropine $(1 \mu \mathrm{M}) . B, C$, Expanded view of two spontaneous bursts of activity (indicated by arrows in $A$ ), showing temporal delays among the bursts in the four selected areas. $D, E$, Differential images taken successively during the two bursts of excitation shown in $B$ and $C$, respectively. Darker areas indicate the front of the waves, which propagated in a circular direction from area 1 to area $4(D)$, and as a two-dimensional plane wave entering the field of view from the bottom and propagating toward areas 3 and $4(E)$, respectively. The wave in $D$ stopped abruptly before reaching area 1 , the starting point of the wave, suggesting a refractory process immediately after the passage of a wave. Similarly, the wave in $E$ stopped abruptly before reaching area 4, in which a small wave had invaded $\sim 6$ sec earlier (not shown in $E$, but see trace 4 in $A$ ). $F$, Rhythmic waves of spontaneous activity in another E29 retina were completely blocked by $1 \mu$ M strychnine (Strych). $G$, Waves in yet another retina from an E30 rabbit were also blocked by $25 \mu \mathrm{M}$ hexamethonium (HEX).

the effect of strychnine on the spontaneous wave was likely attributable to inhibition of glycine receptors but not ACh receptors (see Discussion). Thus, in addition to nicotinic receptormediated interactions, strychnine-sensitive glycinergic neurotransmission also played an obligatory role in early spontaneous retinal waves of the developing rabbit.

\section{Age-dependent contribution of the glycinergic system}

To understand the role of the glycinergic system in spontaneous retinal waves at different stages of development, the effect of strychnine on the wave was examined in rabbits at various perinatal ages. Between E29 and P0, the waves could be completely and reversibly blocked by $0.5-4 \mu \mathrm{M}$ strychnine (Figs. $1 F, 2 A$ ). However, just one day after birth (P1), similar concentrations
(1-4 $\mu \mathrm{M})$ of strychnine no longer blocked the wave. Starting from $\mathrm{P} 2$, strychnine began to enhance the wave by increasing the wave frequency and amplitude $(\Delta F / F)$ (Fig. $2 B)$. The enhancement produced by strychnine increased gradually with age, indicating a gradual development of glycinergic inhibition as the retina matured. Finally, at P7 or older, spontaneous rhythmic bursts were infrequently detected in the ganglion cell layer under physiological recording conditions, consistent with previous results from the ferret retina that spontaneous waves cease to occur shortly before eye opening (Wong et al., 1993). Significantly, however, strychnine $(4 \mu \mathrm{M})$ was effective in inducing waves in these quiescent retinas (Fig. $2 C$ ). Within a few minutes of bath application of strychnine $(2-4 \mu \mathrm{M})$, rhythmic waves were induced in $\sim 30 \%$ of 
A

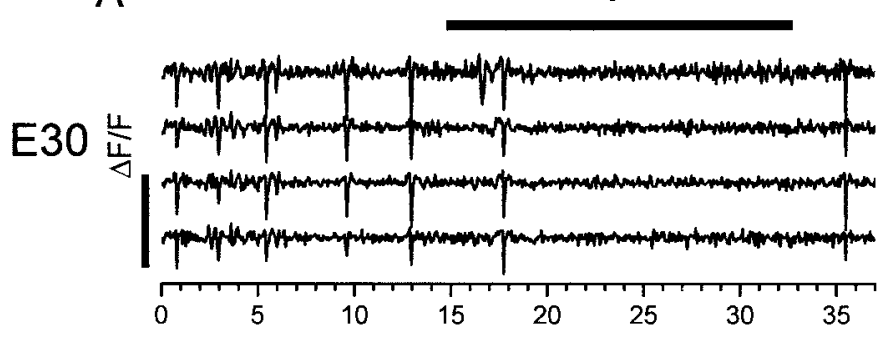

B

P5

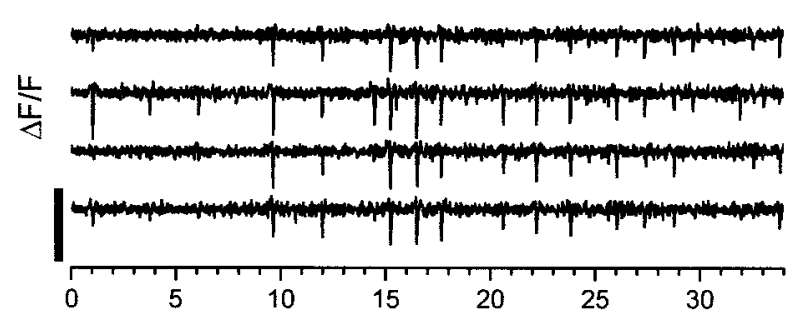

C

P9

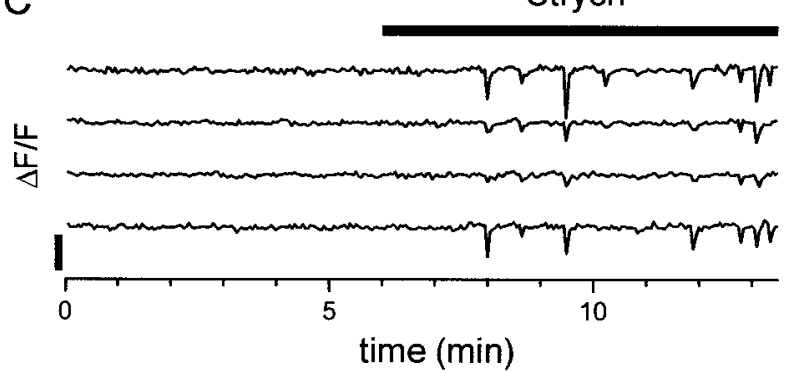

Figure 2. Transition from an excitatory to an inhibitory role of the glycinergic input in retinal waves. $A$, Early spontaneous waves from an E30 retina were completely and reversibly blocked by $2 \mu \mathrm{M}$ strychnine. $B$, Strychnine at the same concentration as in $A$ increased the frequency and amplitude of spontaneous waves in a P5 retina. $C$, In a P9 retina that had no spontaneous retinal waves, $4 \mu \mathrm{M}$ strychnine induced rhythmic retinal waves. Vertical scale bars, $10 \%$.

the retinas tested between the ages of $\mathrm{P} 7$ and $\mathrm{P} 9$. The waves induced by strychnine had a similar appearance and frequency range to those of spontaneous waves in younger retinas. The oldest retina in which rhythmic bursts of excitation were induced by strychnine was from a P13 (2 d after eye opening) rabbit.

Together, the above results suggest that the glycinergic system underwent a transition in its overall contribution to rhythmic retinal waves. This transition is consistent with a change from an excitatory to an inhibitory glycinergic drive for the wave (Fig. 3). The time course of this transition closely correlated with that of the emergence of the glutamatergic and muscarinic drives in spontaneous waves in the rabbit retina (Zhou and Zhao, 2000), suggesting a highly coordinated transformation in neurotransmitter interactions in the inner plexiform layer during this crucial developmental period. The ability of strychnine to induce rhythmic waves in more mature $(\mathrm{P} 7-\mathrm{P} 9)$ retinas also suggests that glycinergic (as well as GABAergic; see below) inhibition may contribute to the eventual disappearance of spontaneous waves just before eye opening.

Simultaneous patch-clamp recordings and fluorescence imaging in the flat-mount retina also demonstrated that strychnine had opposite effects on synaptic-like currents in retinal ganglion cells

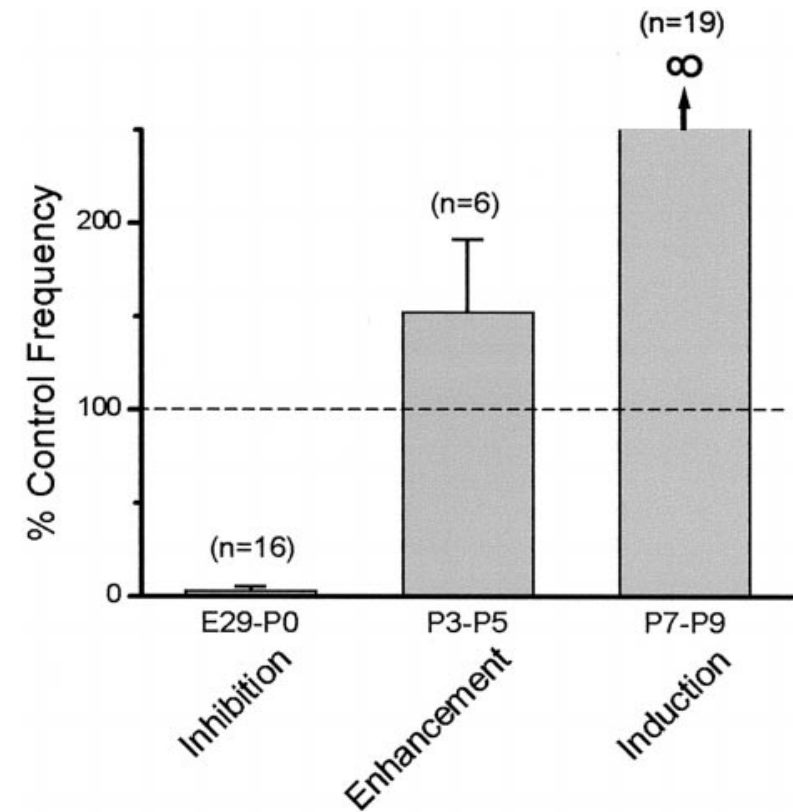

Figure 3. Summary of age-dependent effects of strychnine $(0.5-4 \mu \mathrm{M})$ on rhythmic retinal waves (expressed in percentage of control wave frequency). Bath application of strychnine nearly completely inhibited the spontaneous wave between E29 and P0, increased the frequency of spontaneous waves between P3 and P5, and induced rhythmic waves in quiescent retinas (percentage of wave frequency became infinite) between P7 and P9. Error bars indicate SD. Numbers in parentheses indicate the total number of experiments pooled in each age group. In the P7-P9 group, waves were induced in seven experiments.

during early and late spontaneous retinal waves. Figure $4 A$ shows spontaneous bursts of compound synaptic-like currents recorded under voltage clamp from an E30 ganglion cell. Application of 4 $\mu \mathrm{M}$ strychnine readily abolished the rhythmic currents in this cell (Fig. $4 A, B$ ). On the other hand, application of the same concentration strychnine in a $\mathrm{P} 4$ retina significantly enhanced the amplitude and frequency of both the compound synaptic currents (Fig. $4 C-E$ ) and the rhythmic waves of $\mathrm{Ca}^{2+}$ transients (Fig. $4 F-H)$. The glycinergic system thus played a direct and agedependent role in mediating synaptic interactions and influencing synaptic efficacy during spontaneous retinal waves.

\section{Glycinergic and GABAergic systems played different roles in spontaneous retinal waves}

During early development, GABA is known to provide an excitatory drive in many regions of the nervous system (Luhmann and Prince, 1991; Yuste and Katz, 1991; Zhang et al., 1991; Chen et al., 1996; Huang and Redburn, 1996; Rohrbough and Spitzer, 1996; Fischer et al., 1998). Because nearly all amacrine cells are believed to use either glycine or GABA as their neurotransmitter (Massey and Redburn, 1987), it might be expected that the GABAergic and glycinergic systems both contributed to the overall excitability of the network that supports the early retinal wave. Indeed, application of glycine $(300 \mu \mathrm{M})$ or GABA $(300 \mu \mathrm{M})$ to the E30 retina reversibly blocked the spontaneous wave (Fig. 5A), suggesting that constant activation and, most likely, desensitization of glycine and GABA receptors disrupted the mechanism of spontaneous wave production. Constant application of ACh also abolished the early retinal wave (Zhou and Zhao, 2000). Because the rhythmic generation of retinal waves is most likely associated with rhythmic release of neurotransmitters, the constant presence 
Figure 4. Patch-clamp recordings and optical measurement of effects of strychnine on synaptic inputs to ganglion cells during retinal waves. $A$, Whole-cell patch-clamp recording from a ganglion cell in a flatmount E30 retina at a holding potential of $-70 \mathrm{mV}$, showing bursts of synaptic-like currents that were reversibly blocked by 4 burst indicated by the arrow in $\mathrm{A}$. $\mathrm{C}-\mathrm{H}$, Simultaneous patch clamp from a $\mathrm{P} 4$ ganglion cell and imaging from an area surrounding the cell, showing bursts of synaptic currents $(C)$ in close correlation with fluorescence intensity changes associated with spontaneous retinal waves $(F)$. The magnitude and the frequency of both the bursting currents $(D)$ and the relative changes in fluorescence intensity $(G)$ were significantly increased after the application of $4 \mu \mathrm{M}$ strychnine $(E, H)$. Traces in $A$ and $C$ were filtered at $3 \mathrm{~Hz}\left(f_{\mathrm{c}}\right.$, Bessel $)$ and digitized at $10 \mathrm{~Hz}$, whereas those in $B, D$, and $E$ were filtered at $200 \mathrm{~Hz}$ and digitized at $500 \mathrm{~Hz}$.

Figure 5. A, Spontaneous waves in an E30 retina were blocked by bath applications of glycine (Gly; numbers in parentheses indicate micromolar agonist concentrations) and GABA $(300 \mu \mathrm{M})$. The waves were significantly reduced by $200 \mu \mathrm{M}$ glycine and completely blocked by $300 \mu \mathrm{M}$ glycine in a reversible manner. Application of $300 \mu \mathrm{M}$ GABA in the same retina also completely blocked the wave. Recovery of waves was achieved after washing out GABA and adding $100 \mu \mathrm{M}$ picrotoxin (PIC) to the bath solution. $B$, Opposing effects of picrotoxin and strychnine (Strych) on spontaneous waves in a P0 retina. The waves were enhanced, in both amplitude $(\Delta F / F)$ and frequency, by picrotoxin $(30 \mu \mathrm{M})$ but were completely blocked by strychnine $(4 \mu \mathrm{M})$. $C$, Blockade of spontaneous waves in a $\mathrm{P} 0$ retina by strychnine $(4 \mu \mathrm{M})$ in the presence of picrotoxin $(100 \mu \mathrm{M})$, which had enhanced the waves by blocking $\mathrm{GABA}_{\mathrm{A}}$ and $\mathrm{GABA}_{\mathrm{C}}$ receptors. $\mu \mathrm{M}$ strychnine. $B$, An expanded view of a
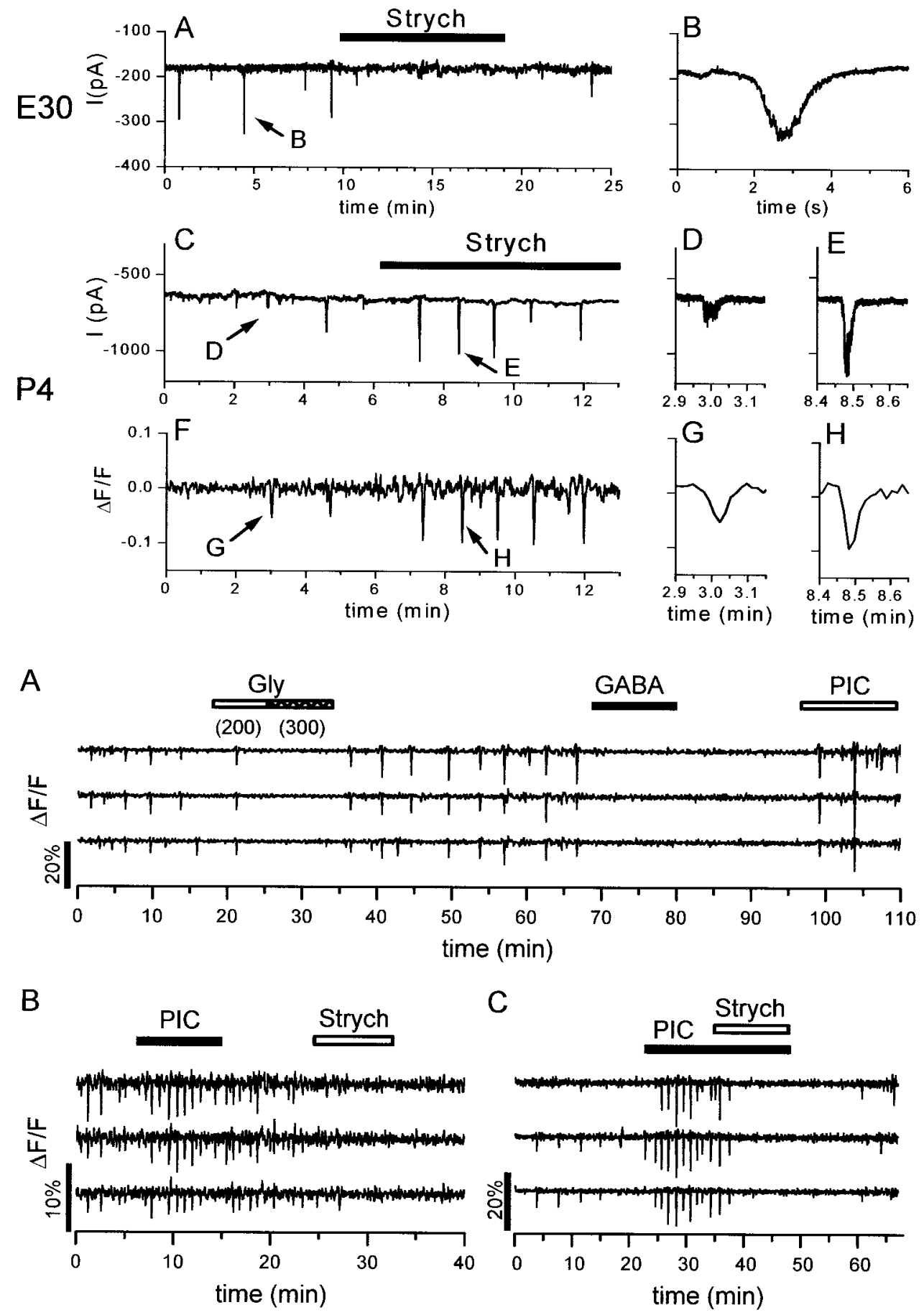

of exogenous agonists, whether excitatory or inhibitory, could conceivably block the endogenous rhythmic activity.

To determine whether endogenous GABA played a role in spontaneous wave formation and whether the ionotropic GABAergic system also provided an excitatory drive for the early wave and an inhibitory drive for the late wave, antagonists to $\mathrm{GABA}_{\mathrm{A}}$ and $\mathrm{GABA}_{\mathrm{C}}$ receptors were tested in rabbits starting from the age of E26. In contrast to the effect of strychnine on the early retinal wave, antagonists to $\mathrm{GABA}_{\mathrm{A}}$ (SR-95531, bicuculline, and picrotoxin) and $\mathrm{GABA}_{\mathrm{C}}$ receptors (picrotoxin) never blocked the early retinal wave. Instead, these antagonists increased the frequency and the peak amplitude $(\Delta F / F)$ of the early wave between E29 and P0. In the youngest rabbit retina tested
(E26, equivalent to P4 in ferret), the enhancement of waves produced by SR-95531 $(50 \mu \mathrm{M})$ or picrotoxin $(50-100 \mu \mathrm{M})$ was minimal and lasted transiently for only a few minutes, during which the waves seemed to become spatially larger, although the wave frequency increased little (data not shown). GABA $(25 \mu \mathrm{M})$ was sufficient to reversibly abolish the waves at E26, suggesting GABA receptors, possibly both $\mathrm{GABA}_{\mathrm{A}, \mathrm{C}}$ and $\mathrm{GABA}_{\mathrm{B}}$ types, were functional at this ages. As the animal reached E29-P0, picrotoxin $(30-100 \mu \mathrm{M})$ or SR-95531 $(50 \mu \mathrm{M})$ clearly enhanced the wave, although strychnine completely blocked the wave in the same retinas (Fig. 5B). A direct interpretation of this result would be that the ionotropic GABAergic system had an overall inhibitory influence on the spontaneous wave, whereas the glycinergic 


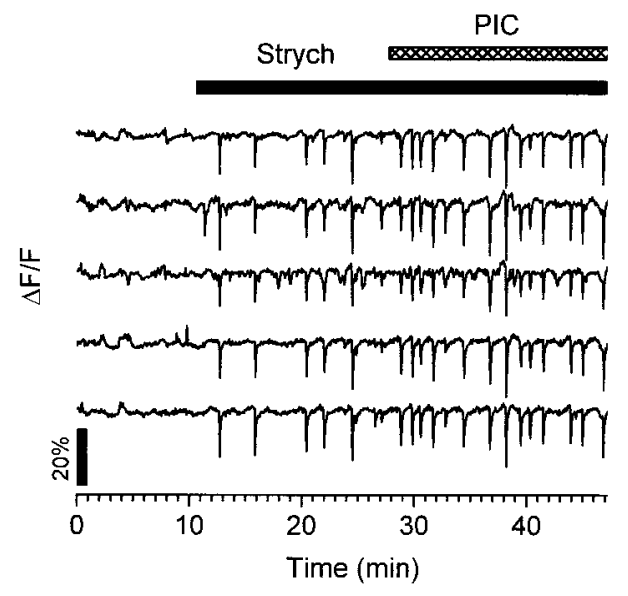

Figure 6. Additive effects of strychnine (Strych; $4 \mu \mathrm{M})$ and picrotoxin $(P I C ; 50 \mu \mathrm{M})$ on late retinal waves in a P3 retina. The retina had few waves under the control condition. Application of strychnine increased the wave amplitude and frequency tremendously. Picrotoxin further enhanced the waves in an additive manner.

system provided an excitatory drive for the wave at this age. Obviously, because the drugs were applied to the entire retina, the effects of the drugs only indicate the overall contributions of glycinergic and GABAergic systems and may not reflect all individual synaptic contributions in these systems. On the other hand, the opposing effects of picrotoxin and strychnine cannot be explained by a glycinergic inhibition of the GABAergic system, because strychnine blocked the wave even when ionotropic GABA receptors had already been blocked by picrotoxin (Fig. $5 C$ ).

As expected, after the glycinergic input changed from an excitatory to an inhibitory drive in rabbits older than P1, strychnine and picrotoxin both strengthened the spontaneous wave. The enhancing effects of strychnine and picrotoxin (or SR-95531; data not shown) on retinal waves were additive between the ages of P2 and P9 (Fig. 6). In general, SR-95531 or picrotoxin produced a much more robust enhancement of the late retinal wave than did strychnine, suggesting the GABAergic input was the stronger of the two inhibitory forces. Like strychnine, picrotoxin or SR-95331 could also induce rhythmic waves in older (older than P7) retinas that were quiescent under the control condition.

\section{Properties of glycine and GABA receptors of developing ganglion cells}

To determine whether the opposite effects of strychnine and picrotoxin on the early retinal wave in rabbits could be attributed to unusual properties of glycine and GABA receptors in the developing rabbit retina, pharmacological and physiological properties of glycine- and GABA-evoked responses in E29-P0 ganglion cells were characterized with patch clamp in retinal whole mounts. Experiments shown in Figure 7 compared the specificity of strychnine and picrotoxin in blocking glycine- and GABAactivated conductances. Bath application of $4 \mu \mathrm{M}$ strychnine blocked $80 \%$ of the currents evoked by puffs of 2 mm glycine (Fig. $7 A$ ) but only $10 \%$ of the currents evoked by 2 mM GABA puffs (Fig. 7B), suggesting that strychnine at the concentration used was highly selective for glycine receptors as opposed to GABA receptors. Because the final concentration of agonists was difficult to determine with puff application, no attempt was made in these experiments to determine the efficacy of strychnine in blocking glycine responses. However, because strychnine is believed to be a competitive blocker (Zhou et al., 1993; Han et al., 1997), the
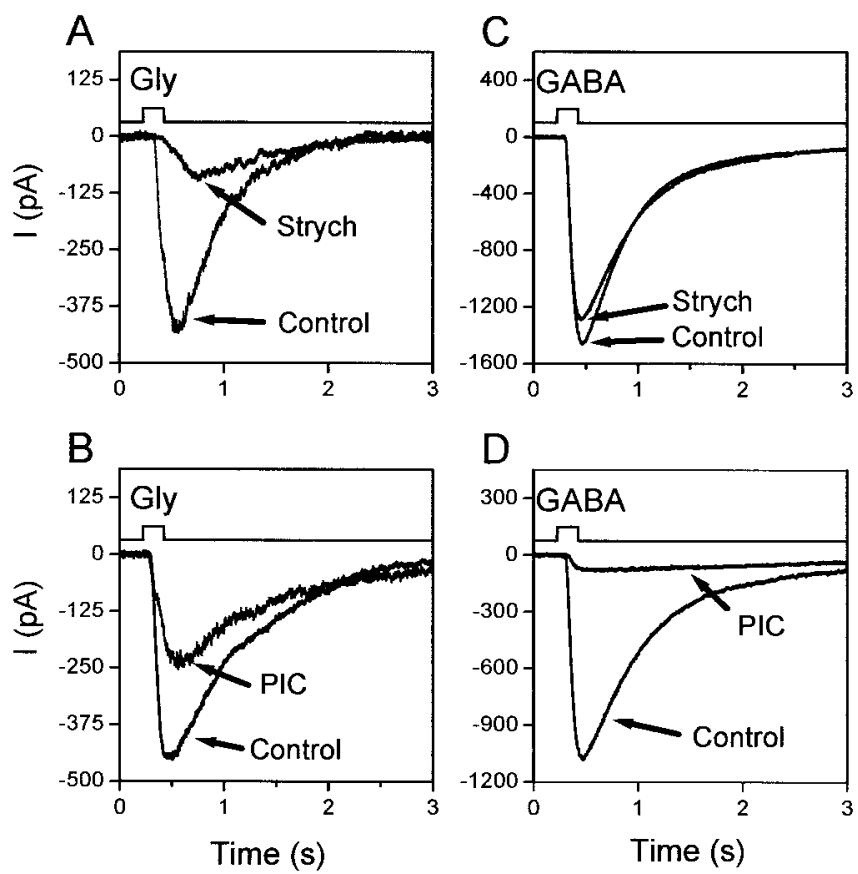

Figure 7. Pharmacology of glycine (Gly)- and GABA-evoked currents from ganglion cells under whole-cell voltage clamp at $-70 \mathrm{mV}$ in an E29 whole-mount retina. The agonists were applied by pressure injection from a puffer pipette $(1 \mu \mathrm{m}$ in tip diameter) containing $3 \mathrm{~mm}$ of respective agonist in HEPES-based Ames medium. The timing of the puffs is indicated by the pulse shown on the top of each panel. Antagonists [ $4 \mu \mathrm{M}$ strychnine (Strych) in $A$ and $C ; 50 \mu \mathrm{M}$ picrotoxin $(P I C)$ in $B$ and $D$ ] were applied by bath perfusion after control responses were first recorded in HEPES-based Ames medium. Currents were filtered at $200 \mathrm{~Hz}\left(f_{\mathrm{c}}\right.$, eight-pole Bessel) and digitized at $500 \mathrm{~Hz}$.

residual $\sim 20 \%$ of the glycine current in the presence of $4 \mu \mathrm{M}$ strychnine (Fig. 1 $A$ ) could be attributable to a relatively high concentration of glycine applied to the cell. It is also possible and, perhaps, more likely that at least a subpopulation of the glycine receptors had a relatively low sensitivity to strychnine, as reported previously in a variety of developing neurons (Becker et al., 1988; Betz, 1991; Ito and Cherubini, 1991; Wu et al., 1995; Flint et al., 1998) and in adult retinal ganglion cells (Han et al., 1997). The relatively slower kinetics of the residual response compared with that of the control response in Figure $7 A$ was also consistent with that reported for glycine receptors with lower strychnine sensitivity (Becker et al., 1988; Betz, 1991; Ito and Cherubini, 1991; Wu et al., 1995; Han et al., 1997; Flint et al., 1998).

On the other hand, bath application of $30 \mu \mathrm{M}$ picrotoxin nearly completely blocked the responses to $2 \mathrm{~mm}$ GABA puffs (Fig. 7D) but reduced only $<50 \%$ of the responses to puffs of $2 \mathrm{~mm}$ glycine (Fig. $7 C$ ). Thus, at least qualitatively, picrotoxin was much more effective in inhibiting GABA-induced than glycine-induced currents in developing rabbit retinal ganglion cells. Although it partially inhibited glycine-induced responses, picrotoxin was used in many of the experiments reported here to ensure that $\mathrm{GABA}_{\mathrm{C}}$ receptors, if present, were also blocked. However, it is important to point out that all of the effects of picrotoxin on the wave were confirmed by the use of the more selective $\mathrm{GABA}_{\mathrm{A}}$ receptor antagonist SR-95531.

Another plausible reason for the opposing effects of strychnine and picrotoxin (or SR-95531) on the early wave might be a difference in ionic selectivity between glycine and GABA recep- 


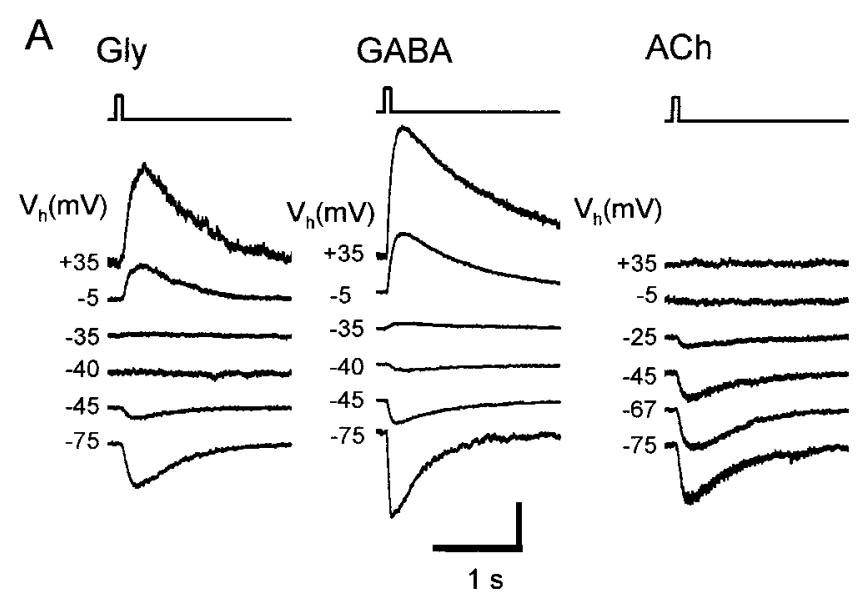

B

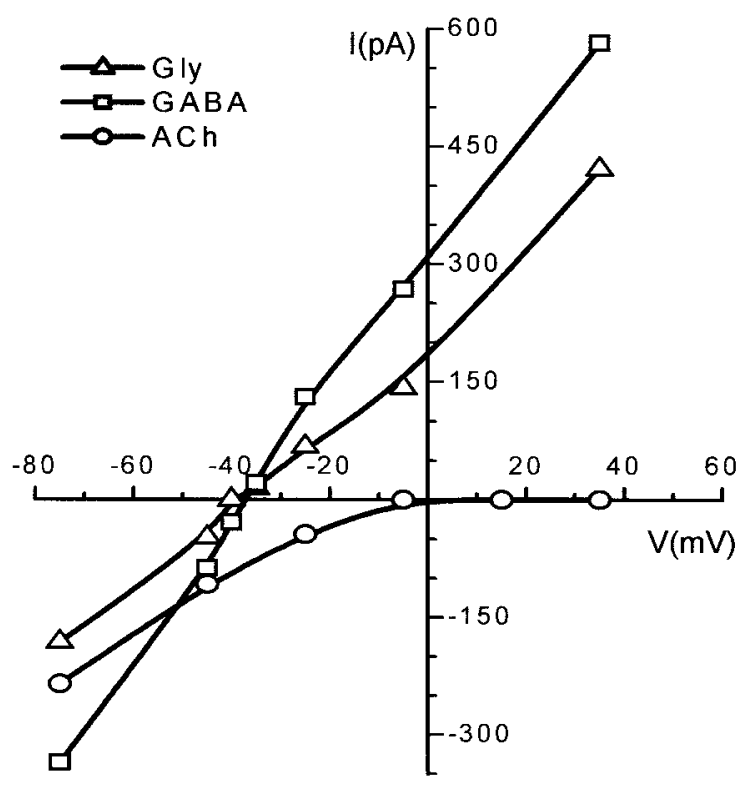

Figure 8. Current-voltage relationships of responses to glycine (Gly), GABA, and ACh from ganglion cells in $\mathrm{P} 0$ rabbit retinal flat mounts. $A$, Responses to glycine $(2 \mathrm{mM})$ and GABA $(2 \mathrm{mM})$ were recorded from the same ganglion cell, whereas those to ACh $(1 \mathrm{mM})$ were from a different ganglion cell. The drugs were puffed to the vicinity of the cell body via small-tip pipettes pulled from two-barrel, $\theta$-shaped glass tubing. Recordings were made in Ames medium under whole-cell voltage clamp with a pipette solution described in Materials and Methods. Top traces in $A$ indicate the timing of the puffs. Vertical scale bars: Gly and ACh currents, $200 \mathrm{pA}$; GABA responses, $400 \mathrm{pA}$. $B, I-V$ curves for peak responses shown in $A$. The magnitude of GABA currents was reduced by a factor of 2 before being plotted in the $I-V$ curve.

tors during development. To address this issue, the currentvoltage relationship of glycine- and GABA-evoked responses was measured in same ganglion cells under whole-cell voltage clamp. The agonists were delivered via a two-barrel puffer pipette (pulled from a $\theta$-tube) to the vicinity of the cell body, in which space clamp and intracellular dialysis were presumably well controlled. Figure 8 shows $I-V$ curves for glycine- and GABA-evoked responses from the same ganglion cell and the $I-V$ curve for ACh-induced responses from a different ganglion cell. Notably, the reversal potential (approximately $-39 \mathrm{mV}$ ) was nearly identical for glycine and GABA currents and was close to the calculated equilibrium for $\mathrm{Cl}^{-}\left(\mathrm{E}_{\mathrm{Cl}}\right.$ of $\left.-48 \mathrm{mV}\right)$, suggesting that the two conductances had similar relative ionic selectivity for $\mathrm{Cl}^{-}$. The deviation of the measured reversal potentials from the calculated $\mathrm{E}_{\mathrm{C} 1}$ may be attributable, in part, to the relative permeability of these channels for $\mathrm{HCO}_{3}^{-}$(Kulik et al., 2000). At the same agonist concentration $(2 \mathrm{mM})$, the GABA currents were a few folds larger than the glycine currents; however, the $I-V$ curves for both GABA and glycine were nearly linear in the voltage range tested, as opposed to the completely inward-rectifying $I-V$ relationship of the cholinergic responses (Fig. 8).

Together, these results showed no unusual pharmacology (except for the well known low affinity of strychnine for glycine receptors during development) or significant differences in relative ionic selectivity between glycine- and GABA-gated $\mathrm{Cl}^{-}$ channels in ganglion cells of the developing rabbit retina.

\section{Contributions of $\mathrm{K}-\mathrm{Cl}$ cotransporters and $\left[\mathrm{Cl}^{-}\right]_{\mathrm{i}}$ to retinal waves}

Given that the opposing effects of strychnine and picrotoxin on the early wave were not likely caused by unusual pharmacology or selectivity of the respective receptors (at least in ganglion cells), the contribution of intracellular $\mathrm{Cl}^{-}$distribution to the excitability of retinal ganglion and interneurons was investigated. It has been reported recently that the excitatory effect of GABA and glycine during early development can be primarily attributed to a developmental delay in the expression of $\mathrm{K}-\mathrm{Cl}$ cotransporters (KCCs), which help to maintain a low $[\mathrm{Cl}]_{\mathrm{i}}$ in mature neurons (Thompson and Gahwiler, 1989). In particular, the expression of KCC2, a neuron-specific K-Cl cotransporter (Payne et al., 1996), has been shown to be highly age-dependent and to appear in the rat retina at approximately the time of birth ( Vu et al., 2000). To assess the influence of KCCs on spontaneous retinal waves, a specific blocker of KCCs, $R(+)$-butylindazone (DIOA) (Garay et al., 1988; Gibson et al., 1998), was used as a means of altering $[\mathrm{Cl}]_{\mathrm{i}}$ during the course of wave development in the rabbit retina. As shown in Figure $9 A$, bath application of DIOA to a $\mathrm{P} 3$ rabbit retina dramatically enhanced the spontaneous wave by increasing both the wave frequency and amplitude. The effects of DIOA developed quickly (within $\sim 2-4$ min of application), suggesting a rather rapid redistribution of $[\mathrm{Cl}]_{\mathrm{i}}$ after the blockade of KCCs. As described above, both glycinergic and GABAergic systems provided an inhibitory input to the spontaneous retinal wave at P3 (the late wave). Thus, the enhancement of late retinal waves by DIOA was consistent with an increase in $[\mathrm{Cl}]_{\mathrm{i}}$, which reduced the glycinergic and GABAergic inhibition of the wave and might possibly even converted these inhibitory inputs into excitatory ones.

When DIOA was applied to rabbit retinas younger than $\mathrm{P} 0$, the spontaneous wave (the early wave) was also dramatically enhanced (Fig. 9B). Interestingly, in the presence of DIOA, picrotoxin no longer showed any significant excitatory effect on the early wave (if anything, it seemed to have reduced the wave frequency slightly) (Fig. 9B). These results suggest that the early GABAergic inhibition of the wave was mediated by an inhibitory $\mathrm{Cl}^{-}$conductance and that the DIOA-induced increases in $[\mathrm{Cl}]_{\mathrm{i}}$ eliminated this inhibition.

Can the removal of GABAergic inhibition account for all the enhancement of the early spontaneous wave by DIOA? To address this question, DIOA was tested in the prenatal rabbit retina after the application of picrotoxin or SR-9553, which blocked GABAergic inhibition and enhanced the wave (Fig. 9C). Under this condition, DIOA further enhanced the waves dramatically. The waves in the presence of picrotoxin and DIOA could still be 

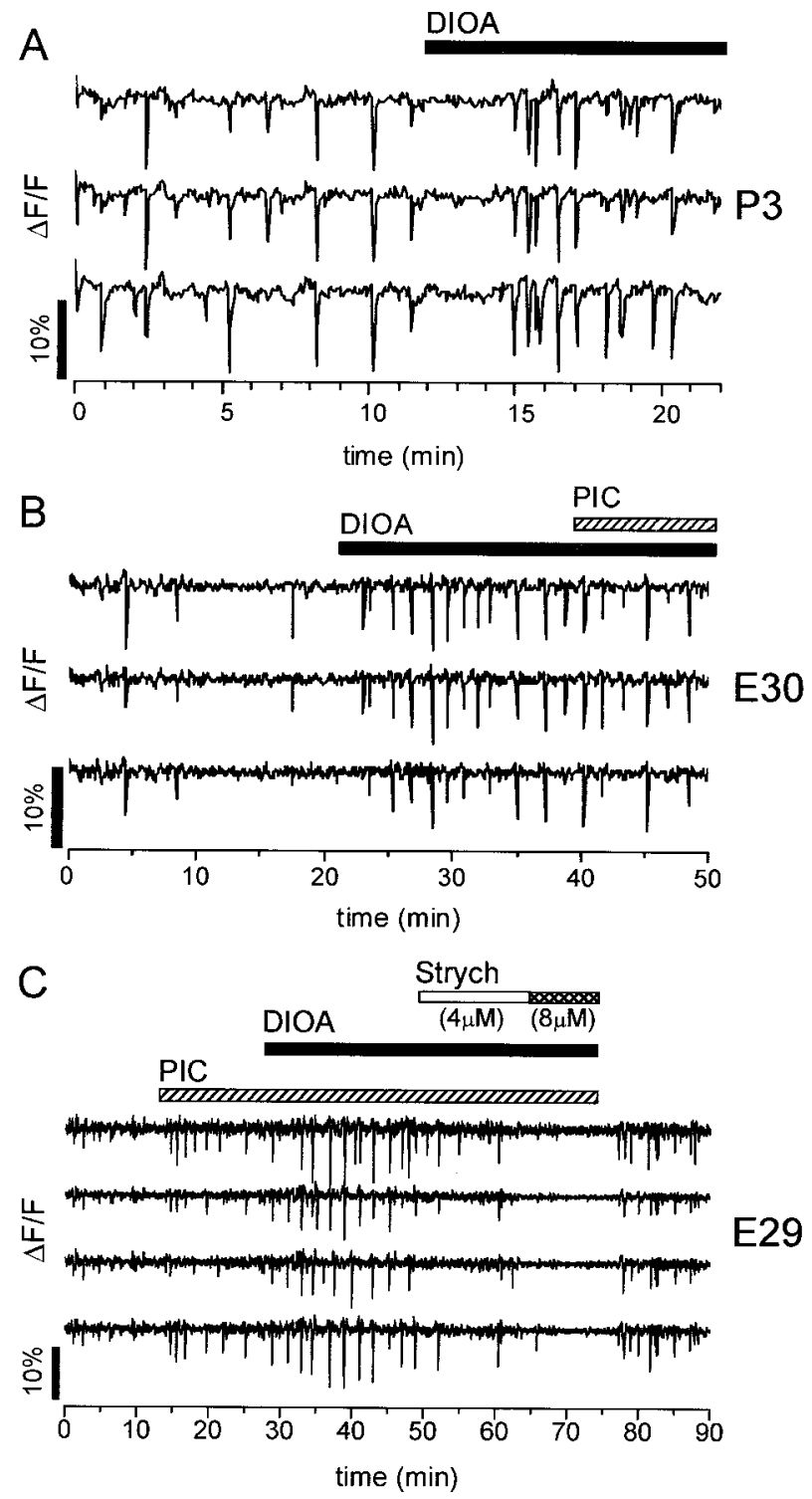

Figure 9. Effects of DIOA on spontaneous retinal waves. A, DIOA (80 $\mu \mathrm{M})$ significantly increased the frequency of late retinal waves in a P3 retina. $B$, Enhancement of early spontaneous waves by $80 \mu \mathrm{M}$ DIOA in an E30 retina. Notice that picrotoxin $(P I C ; 50 \mu \mathrm{M})$ no longer enhanced the early wave in the presence of DIOA. $C$, Enhancement of spontaneous waves in an E29 retina by picrotoxin $(30 \mu \mathrm{M})$ and further enhancement by the addition of $80 \mu \mathrm{M}$ DIOA. Strychnine (Strych) completely blocked the waves in the presence of both picrotoxin and DIOA.

completely and reversibly blocked by strychnine, although a slightly higher concentration of the antagonist $(8 \mu \mathrm{M})$ was necessary to produce a complete block (Fig. $9 C$ ). These results are consistent with the idea that glycine provided an obligatory drive for the early spontaneous retinal wave. They further suggest that, although the glycinergic drive seemed excitatory at E29-P0, low levels of $\mathrm{KCC}$ expressions were already present in the glycinergic system at this age, so that the blockade of these transporters further increased the excitability of the glycinergic input.

The above experiments using DIOA demonstrated that KCC and $[\mathrm{Cl}]_{\mathrm{i}}$ had direct influences on the excitability of the glycinergic and GABAergic systems during the course of spontaneous waves in the rabbit retina. They raised an appealing possibility that the distribution of $[\mathrm{Cl}]_{\mathrm{i}}$ may be different between the glycinergic and GABAergic systems during certain stages of development, resulting in opposite excitability of the two systems. This difference in $[\mathrm{Cl}]_{\mathrm{i}}$ distribution might be caused by different levels of KCC expression in cells involved in these two neurotransmitter systems. It is also possible that KCCs distribution is differentially regulated at GABA and glycine synapses, such that the GABAergic synapses might be surrounded by more KCCs than might the glycinergic synapses. Further investigation is necessary to directly test these possibilities (see Discussion).

\section{DISCUSSION}

\section{Role of glycinergic and GABAergic systems in retinal waves}

The above results show that the early retinal wave in rabbit depends critically on strychnine-sensitive neurotransmission, suggesting that an obligatory glycinergic role in wave formation. Thus, although the cholinergic system has been thought to provide the primary excitatory drive for the early spontaneous wave in the mammalian retina (Feller et al., 1996; Bansal et al., 2000; Zhou and Zhao, 2000), cholinergic neurotransmission alone is not sufficient. At least one additional fast neurotransmitter system, the glycinergic system, is also required as an essential excitatory drive for the early wave. This finding also indicates that, in addition to cholinergic amacrine cells, other interneurons also function as critical components of the network mediating the early retinal wave. In the adult rabbit retina, cholinergic and glycinergic amacrine cells have been proposed to form serial and feedback connections with each other (Neal and Cunningham, 1995).

Strychnine is also known to block nicotinic receptors containing $\alpha 7$ and $\alpha 9$ subunits (Seguela et al., 1993; Elgoyhen et al., 1994) and certain other nicotinic receptor types expressed in Xenopus oocytes (Garcia-Colunga and Miledi, 1999), raising the possibility that the blockade of the early wave by strychnine might be attributable to inhibition of the nicotinic system. This possibility, however, is not likely for the following three reasons. First, strychnine $(4 \mu \mathrm{M})$ did not have a significant effect on ACh-evoked $\left[\mathrm{Ca}^{2+}\right]$ rises in the ganglion cell layer or ACh-induced currents in E29 ganglion cells (see Results). Second, $\alpha$-bungarotoxin, which blocks strychnine-sensitive, $\alpha 7$ - and $\alpha 9$-containing nicotinic receptors (Elgoyhen et al., 1994; Zhang et al., 1994), had no effect on the early spontaneous wave in rabbit (Zhou and Zhao, 2000) or ferret (Feller et al., 1996). Third, strychnine changed from blocking to enhancing the wave at $\mathrm{P} 0-\mathrm{P} 1$, whereas nicotinic antagonists continued to block the spontaneous wave until after P3 (Fig. 10). Thus, there was a window of at least 1-2 d, during which the waves were blocked by nicotinic antagonists but not by strychnine, which in fact slightly enhanced the wave at this age. Together, these results suggest that the strychnine blockade of the early wave is attributable to the inhibition of glycine receptors, although the possibility of some strychnine-sensitive cholinergic contribution to the wave cannot be excluded and requires further investigation.

The pharmacology of glycine-induced responses in the early developing rabbit retina seems in agreement with reports that strychnine has a lower affinity for glycine receptors during development (e.g., $\mathrm{IC}_{50}$ of $\sim 5.6 \mu \mathrm{M}$ ) (cf. Flint et al., 1998) than in adulthood (Becker et al., 1988; Betz, 1991; Wu et al., 1995). This low affinity, together with possible species differences, may explain why previous studies of glycinergic contribution to early retinal waves were inconclusive (Fischer et al., 1998). In addition 

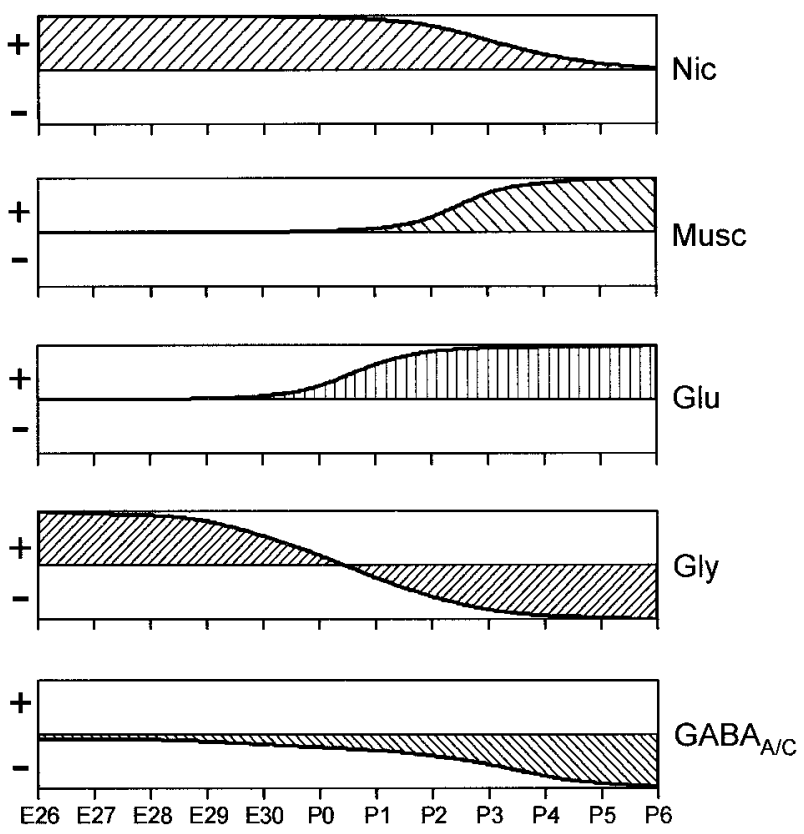

Figure 10. Schematic summary of transitions among basic neurotransmitter systems known to mediate or modulate the spontaneous wave in the rabbit retina. The curves show qualitatively the overall contribution of different transmitter systems to spontaneous retinal waves at various ages. + , Excitatory inputs. - , inhibitory inputs. A transition in excitability occurs when the curve crosses the $x$-axis. Only ionotropic glutamatergic systems are included. Nic, Nicotinic; Musc, muscarinic; Glu, glutamatergic; Gly, glycinergic; $G A B A_{A / C}$, GABAergic.

to glycine, it is possible that taurine, which is abundant in the developing rabbit retina (Pow et al., 1994), may also play a role through its action on glycine receptors, as reported in the developing neocortex (Flint et al., 1998).

That the glycinergic contribution to the rabbit retinal wave changes from excitation to inhibition as development proceeds is consistent with previous observations in developing motoneurons that glycine plays a dynamic and age-dependent role (Nishimaru et al., 1996; Singer et al., 1998; Nakayama et al., 1999). Although GABA is commonly found to mediate neuronal excitation during early development, the results reported here add yet another important example of glycine acting as a critical excitatory transmitter in the early developing neuronal network. Interestingly, in rabbits between the ages of E26 and P0 (equivalent to P4-P14 in ferret), picrotoxin or SR-95531 never inhibited the wave, suggesting that ionotropic GABAergic systems did not play an essential role, nor did they provide an overall excitatory drive for the early wave. This conclusion, however, does not exclude the possibility that the $\mathrm{GABA}_{\mathrm{B}}$ system may play a role in the wave, because baclofen seemed to down modulate the wave in the developing rabbit retina (my unpublished observation), similar to that reported in the chick retina (Catsicas and Mobbs, 2001). It also does not rule out the possibility that $\mathrm{GABA}_{\mathrm{A} / \mathrm{C}}$ systems may provide an excitatory drive to subsets of retinal neurons in the developing rabbit, especially before the earliest age tested in this study (E26). Effects of ionotropic GABA receptor antagonists on the early retinal wave have been examined previously in P2-P12 ferret retinas, but the results in ferret have so far remained inconsistent with respect to whether or not these antagonists had an effect on wave dynamics (Fischer et al., 1998; Stellwagen et al., 1999).

\section{Coordinated contributions from multiple neurotransmitter systems}

The finding of an essential glycinergic role in the early retinal wave formation demonstrates the importance of coordinated contributions from multiple neurotransmitter systems in wave generation and propagation. Recent studies have indicated that different transmitter systems mediate retinal waves at different developmental stages and that correlated transitions between different systems occur during crucial periods of retinal development (Bansal et al., 2000; Wong et al., 2000; Zhou and Zhao, 2000). Results from this study have gone a step further to show that, even within a single developmental stage, the formation of spontaneous waves requires more than one fast excitatory drive. The interactions and transitions among the currently known transmitter systems that underlie retinal waves in the developing rabbit are summarized in Figure 10. For the early retinal wave (younger than $\mathrm{P} 0-\mathrm{P} 1$ ), both nicotinic and glycinergic systems provided essential fast excitatory drive. At this developmental stage, the ionotropic GABAergic system did not play an obligatory role in wave formation, although it seemed to provide an overall inhibitory drive, which was initially weak at E26 but then became stronger at E29-P0. The ionotropic glutamatergic and muscarinic system also did not play a significant role in the wave formation at this stage.

Immediately after birth, a number of dramatic transitions occurred within a short period of time. First, a fast glutamatergic drive emerged quickly (Zhou and Zhao, 2000), with a time course that mirrored the transition of the glycinergic system from an excitatory to an inhibitory drive (Fig. 10). The glutamatergic system provided a strong excitatory input to the late wave and eventually replaced the nicotinic and glycinergic systems as the major fast excitatory drive for the wave. Second, a transition between the nicotinic and muscarinic systems took place concomitantly, such that the muscarinic system replaced the nicotinic system in providing an obligatory cholinergic network for the wave (Zhou and Zhao, 2000). The decline of the excitatory contribution from the nicotinic system began immediately after birth but with a time course slightly slower than the time courses of the glycinergic transition and the emergence of the muscarinic and glutamate systems (Zhou and Zhao, 2000). As a result, before the nicotinic drive for the wave disappeared completely, there was a window of 2-3 d (P2-P4), during which both glutamate and nicotinic systems appear to provide essential excitatory drives for the wave (Zhou and Zhao, 2000). Finally, like the glycinergic system, the inhibitory GABAergic drive for the late wave developed quickly after birth and became very strong by the end of the first postnatal weak. The fact that strychnine and picrotoxin could induce retinal waves after the first postnatal weak when spontaneous waves became rarely detectable suggests that the inhibitory amino acid neurotransmitter systems contributed to the eventual disappearance of spontaneous retinal waves.

In addition to the above mentioned neurotransmitter systems, other systems, such as adenosine (Stellwagen et al., 1999), whose agonist NECA enhanced both the early and late waves in the rabbit retina (Z. J. Z hou and D. Z hao, unpublished observation), and $\mathrm{GABA}_{\mathrm{B}}$ (Catsicas and Mobbs, 2001) may also be important mediators or modulators of retinal waves. Thus, it appears that the underlying mechanism for retinal waves may involve a rich variety of neurotransmitter and modulator systems interacting in concert. The very involvement of multiple neurotransmitter systems in retinal waves may in turn reflect an important require- 
ment for retinal waves in the normal development of each of the participating neurotransmitter systems in the retina, as suggested for glycine receptor clustering in developing spinal neurons (Kirsch and Betz, 1998). This may, in part, explain why different transmitter systems are used at different developmental periods to produce the same phenomenon, retinal waves.

\section{Contribution and distribution of $\mathrm{KCC}$ and $[\mathrm{Cl}]_{\mathrm{i}}$ in the developing retina}

The robust effects of DIOA on the spontaneous wave in the developing rabbit retina suggest a significant contribution of $\mathrm{KCCs}$ and $[\mathrm{Cl}]_{\mathrm{i}}$ to retinal excitability and retinal wave dynamics. This is consistent with recent findings that KCCs expression correlates with a decrease in GABA-mediated shift in reversal potentials (Rivera et al., 1999) and that the expression of KCCs, including the neuron-specific form KCC2 (Payne et al., 1996), is developmentally regulated. Vu et al. (2000) showed recently that immunostaining of $\mathrm{KCC} 2$ in the mouse inner retina increased dramatically during the first postnatal week. Such a developmentally regulated expression of $\mathrm{KCC} 2$ and, perhaps, other $\mathrm{Cl}^{-}$ transporters may underlie both the excitatory nature of the glycinergic system in the early wave and the transition to an inhibitory glycinergic system.

Of particular interest are the differential effects of $\mathrm{GABA}_{\mathrm{A} / \mathrm{C}}$ and glycine antagonists on the early wave, most significantly at approximately the age of E29-E30, indicating that the development of KCCs may occur earlier in the GABAergic than in the glycinergic system. This raises the possibility of a differential expression and distribution pattern of $\mathrm{Cl}^{-}$transporters in the inner retina during certain stages of development. Such a differential distribution pattern may exist within single neurons, e.g., as a result of KCCs clustering around GABAergic postsynaptic sites to produce a localized reduction in $[\mathrm{Cl}]_{\mathrm{i}}$. The idea of localized cellular distribution of KCCs is consistent with recent findings that $\mathrm{KCC} 2$ expression in developing retinal ganglion cells is nonuniform, concentrated in dendrites but lacking in the soma (Vu et al., 2000), and that KCC2 expression is localized to specific dendritic regions of certain bipolar cells (Vardi et al., 2000). A synapse-specific distribution of KCCs would allow neurons in the inner retina, which often receive both GABAergic and glycinergic inputs, to be regulated differentially by GABA and glycine. On the other hand, it is also possible that the differential expression and distribution of KCCs may occur mainly among different cell types in the developing inner retina, such that cells predominantly associated with the GABAergic system may have an earlier and higher level of KCC expression. An indirect support for this notion may also be found in the report by $\mathrm{Vu}$ et al. (2000), which shows that the onset of $\mathrm{KCC} 2$ expression occurs at different ages in different cell types of the rat retina. Finally, it should be pointed out that, although this study examined the overall functional role of glycine and GABA systems, there are numerous cell types within each of these systems. The excitability of and the interactions among various subtypes of glycinergic and GABAergic interneurons should also be taken into consideration in a detailed model for retinal waves.

\section{REFERENCES}

Ames Ad, Nesbett FB (1981) In vitro retina as an experimental model of the central nervous system. J Neurochem 37:867-877.

Bansal A, Singer JH, Hwang BJ, Xu W, Beaudet A, Feller MB (2000) Mice lacking specific nicotinic acetylcholine receptor subunits exhibit dramatically altered spontaneous activity patterns and reveal a limited role for retinal waves in forming $\mathrm{ON}$ and $\mathrm{OFF}$ circuits in the inner retina. J Neurosci 20:7672-7681.
Becker CM, Hoch W, Betz H (1988) Glycine receptor heterogeneity in rat spinal cord during postnatal development. EMBO J 7:3717-3726.

Betz H (1991) Glycine receptors: heterogeneous and widespread in the mammalian brain. Trends Neurosci 14:458-461.

Catsicas M, Mobbs P (2001) $\mathrm{GABA}_{\mathrm{B}}$ receptors regulate chick retinal calcium waves. J Neurosci 21:897-910.

Catsicas M, Bonness V, Becker D, Mobbs P (1998) Spontaneous Ca ${ }^{2+}$ transients and their transmission in the developing chick retina. Curr Biol 8:283-286.

Chen G, Trombley PQ, van den Pol AN (1996) Excitatory actions of GABA in developing rat hypothalamic neurones. J Physiol (Lond) 494:451-464.

Cline HT (1991) Activity-dependent plasticity in the visual systems of frogs and fish. Trends Neurosci 14:104-111.

Constantine-Paton M, Cline HT, Debski E (1990) Patterned activity, synaptic convergence, and the NMDA receptor in developing visual pathways. Annu Rev Neurosci 13:129-154.

Dreher B, Robinson SR (1988) Development of the retinof ugal pathway in birds and mammals: evidence for a common "time-table." Brain Behav Evol 31:369-390.

Elgoyhen AB, Johnson DS, Boulter J, Vetter DE, Heinemann S (1994) Alpha 9: an acetylcholine receptor with novel pharmacological properties expressed in rat cochlear hair cells. Cell 79:705-715.

Feller MB (1999) Spontaneous correlated activity in developing neural circuits. Neuron 22:653-656.

Feller MB, Wellis DP, Stellwagen D, Werblin FS, Shatz CJ (1996) Requirement for cholinergic synaptic transmission in the propagation of spontaneous retinal waves. Science 272:1182-1187.

Fischer KF, Lukasiewicz PD, Wong RO (1998) Age-dependent and cell class-specific modulation of retinal ganglion cell bursting activity by GABA. J Neurosci 18:3767-3778.

Flint AC, Liu X, Kriegstein AR (1998) Nonsynaptic glycine receptor activation during early neocortical development. Neuron 20:43-53.

Garay RP, Nazaret C, Hannaert PA, Cragoe Jr EJ (1988) Demonstration of a $\left[\mathrm{K}^{+}, \mathrm{Cl}^{-}\right]$-cotransport system in human red cells by its sensitivity to [(dihydroindenyl)oxy]alkanoic acids: regulation of cell swelling and distinction from the bumetanide-sensitive $\left[\mathrm{Na}^{+}, \mathrm{K}^{+}, \mathrm{Cl}^{-}\right]$-cotransport system. Mol Pharmacol 33:696-701.

Garcia-Colunga J, Miledi R (1999) Modulation of nicotinic acetylcholine receptors by strychnine. Proc Natl Acad Sci USA 96:4113-4118.

Gibson JS, Speake PF, Ellory JC (1998) Differential oxygen sensitivity of the $\mathrm{K}^{+}{ }_{-} \mathrm{Cl}^{-}$cotransporter in normal and sickle human red blood cells. J Physiol (Lond) 511:225-234.

Goodman CS, Shatz CJ (1993) Developmental mechanisms that generate precise patterns of neuronal connectivity. Cell [Suppl] 72:77-98.

Han Y, Zhang J, Slaughter MM (1997) Partition of transient and sustained inhibitory glycinergic input to retinal ganglion cells. J Neurosci 17:3392-3400.

Huang BO, Redburn DA (1996) GABA-induced increases in $\left[\mathrm{Ca}^{2+}\right]_{\mathrm{i}}$ in retinal neurons of postnatal rabbits. Vis Neurosci 13:441-447.

Ito S, Cherubini E (1991) Strychnine-sensitive glycine responses of neonatal rat hippocampal neurones. J Physiol (Lond) 440:67-83.

Katz LC, Shatz CJ (1996) Synaptic activity and the construction of cortical circuits. Science 274:1133-1138.

Kirsch J, Betz H (1998) Glycine-receptor activation is required for receptor clustering in spinal neurons. Nature 392:717-720.

Kulik A, Nishimaru H, Ballanyi K (2000) Role of bicarbonate and chloride in GABA- and glycine-induced depolarization and $\left[\mathrm{Ca}^{2+}\right]_{i}$ rise in fetal rat motoneurons in situ. J Neurosci 20:7905-7913.

Luhmann HJ, Prince DA (1991) Postnatal maturation of the GABAergic system in rat neocortex. J Neurophysiol 65:247-263.

Lukasiewicz PD, Werblin FS (1990) The spatial distribution of excitatory and inhibitory inputs to ganglion cell dendrites in the tiger salamander retina. J Neurosci 10:210-221.

Maffei L, Galli-Resta L (1990) Correlation in the discharges of neighboring rat retinal ganglion cells during prenatal life. Proc Natl Acad Sci USA 87:2861-2864.

Masland RH (1977) Maturation of function in the developing rabbit retina. J Comp Neurol 175:275-286.

Massey SC, Redburn DA (1987) Transmitter circuits in the vertebrate retina. Prog Neurobiol 28:55-96.

Meister M, Wong RO, Baylor DA, Shatz CJ (1991) Synchronous bursts of action potentials in ganglion cells of the developing mammalian retina. Science 252:939-943.

Nakayama K, Nishimaru H, Iizuka M, Ozaki S, Kudo N (1999) Rostrocaudal progression in the development of periodic spontaneous activity in fetal rat spinal motor circuits in vitro. J Neurophysiol 81:2592-2595.

Neal MJ, Cunningham JR (1995) Baclofen enhancement of acetylcholine release from amacrine cells in the rabbit retina by reduction of glycinergic inhibition. J Physiol (Lond) 482:363-372.

Nishimaru H, Iizuka M, Ozaki S, Kudo N (1996) Spontaneous motoneuronal activity mediated by glycine and GABA in the spinal cord of rat fetuses in vitro. J Physiol (Lond) 497:131-143.

O'Donovan MJ (1999) The origin of spontaneous activity in developing 
networks of the vertebrate nervous system. Curr Opin Neurobiol 9:94-104.

Payne JA, Stevenson TJ, Donaldson LF (1996) Molecular characterization of a putative $\mathrm{K}-\mathrm{Cl}$ cotransporter in rat brain. A neuronal-specific isoform. J Biol Chem 271:16245-16252.

Penn AA, Riquelme PA, Feller MB, Shatz CJ (1998) Competition in retinogeniculate patterning driven by spontaneous activity. Science 279:2108-2112.

Pow DV, Crook DK, Wong RO (1994) Early appearance and transient expression of putative amino acid neurotransmitters and related molecules in the developing rabbit retina: an immunocytochemical study. Vis Neurosci 11:1115-1134.

Rivera C, Voipio J, Payne JA, Ruusuvuori E, Lahtinen H, Lamsa K, Pirvola U, Saarma M, Kaila K (1999) The $\mathrm{K}^{+} / \mathrm{Cl}^{-}$co-transporter KCC2 renders GABA hyperpolarizing during neuronal maturation. Nature 397:251-255.

Rohrbough J, Spitzer NC (1996) Regulation of intracellular $\mathrm{Cl}^{-}$levels by $\mathrm{Na}^{+}$-dependent $\mathrm{Cl}^{-}$cotransport distinguishes depolarizing from hyperpolarizing GABAA receptor-mediated responses in spinal neurons. J Neurosci 16:82-91.

Seguela P, Wadiche J, Dineley-Miller K, Dani JA, Patrick JW (1993) Molecular cloning, functional properties, and distribution of rat brain $\alpha_{7}$ : a nicotinic channel highly permeable to calcium. J Neurosci 13:596-604.

Sernagor E, Grzywacz NM (1995) Emergence of complex receptive field properties of ganglion cells in the developing turtle retina. J Neurophysiol 73:1355-1364.

Sernagor E, Grzywacz NM (1996) Influence of spontaneous activity and visual experience on developing retinal receptive fields. Curr Biol 6:1503-1508.

Sernagor E, Grzywacz NM (1999) Spontaneous activity in developing turtle retinal ganglion cells: pharmacological studies. J Neurosci 19:3874-3887.

Sernagor E, Eglen SJ, O’Donovan MJ (2000) Differential effects of acetylcholine and glutamate blockade on the spatiotemporal dynamics of retinal waves. J Neurosci 20:RC56(1-6).

Singer JH, Talley EM, Bayliss DA, Berger AJ (1998) Development of glycinergic synaptic transmission to rat brain stem motoneurons. J Neurophysiol 80:2608-2620.

Stellwagen D, Shatz CJ, Feller MB (1999) Dynamics of retinal waves are controlled by cyclic AMP. Neuron 24:673-685.
Thompson SM, Gahwiler BH (1989) Activity-dependent disinhibition. III. Desensitization and GABAB receptor-mediated presynaptic inhibition in the hippocampus in vitro. J Neurophysiol 61:524-533.

Vardi N, Zhang LL, Payne JA, Sterling P (2000) Evidence that different cation chloride cotransporters in retinal neurons allow opposite responses to GABA. J Neurosci 20:7657-7663.

$\mathrm{Vu}$ TQ, Payne JA, Copenhagen DR (2000) Localization and developmental expression patterns of the neuronal $\mathrm{K}-\mathrm{Cl}$ cotransporter (KCC2) in the rat retina. J Neurosci 20:1414-1423.

Wong RO (1999) Retinal waves and visual system development. Annu Rev Neurosci 22:29-47.

Wong RO, Meister M, Shatz CJ (1993) Transient period of correlated bursting activity during development of the mammalian retina. Neuron 11:923-938.

Wong WT, Sanes JR, Wong ROL (1998) Developmentally regulated spontaneous activity in the embryonic chick retina. J Neurosci 18:8839-8852.

Wong WT, Myhr KL, Miller ED, Wong RO (2000) Developmental changes in the neurotransmitter regulation of correlated spontaneous retinal activity. J Neurosci 20:351-360.

Wu SY, Miyazaki T, Dun NJ (1995) Glycine induces two distinct membrane currents in neonatal rat sympathetic preganglionic neurones in vitro. J Physiol (Lond) 483:385-396.

Yuste R, Katz LC (1991) Control of postsynaptic $\mathrm{Ca}^{2+}$ influx in developing neocortex by excitatory and inhibitory neurotransmitters. Neuron $6: 333-344$

Zhang L, Spigelman I, Carlen PL (1991) Development of GABAmediated, chloride-dependent inhibition in CA1 pyramidal neurones of immature rat hippocampal slices. J Physiol (Lond) 444:25-49.

Zhang ZW, Vijayaraghavan S, Berg DK (1994) Neuronal acetylcholine receptors that bind alpha-bungarotoxin with high affinity function as ligand-gated ion channels. Neuron 12:167-177.

Zhou ZJ (1998) Direct participation of starburst amacrine cells in spontaneous rhythmic activities in the developing mammalian retina. J Neurosci 18:4155-4165.

Zhou ZJ, Zhao D (2000) Coordinated transitions in neurotransmitter systems for the initiation and propagation of spontaneous retinal waves. J Neurosci 20:6570-6577.

Zhou ZJ, Fain GL, Dowling JE (1993) The excitatory and inhibitory amino acid receptors on horizontal cells isolated from the white perch retina. J Neurophysiol 70:8-19. 